\title{
Género, cuerpo y amor: un acercamiento a sus formas discursivas y sociales
}

\author{
Genaro Aguirre Aguilar ${ }^{1}$
}

\section{Apenas un acercamiento}

De

entro de la llamada perspectiva de género, el estudio del cuerpo y la sexualidad han ocupado un lugar importante, en virtud de ser éstos los continentes referenciales y de significación cultural desde los cuales es posible señalar, se configura y estructura el mundo social, tanto en la práctica como en el discurso. La teoría que a propósito de ello ha sido desarrollada por investigadoras y académicas feministas, principalmente, ha venido a establecer un edificio discursivo que replantea buena parte de la teoría que sobre el estudio de las relaciones humanas, de la vida y la acción social se había desarrollado.

Desde una visión más bien antropológica, ${ }^{2}$ la producción de conocimientos impulsados desde el movimiento académico feminista rompió con la mirada androcéntrica que dominaba los discursos de la teoría social clásica, promoviendo un descentramiento para poner en escena una lectura crítica, sensible pero rigurosa y distinta, sobre el mundo de vida; donde hombres y mujeres aparecen como agentes sociales analizados profundamente, no sólo en términos biologicistas sino también culturales y retóricos; lo que sin duda supuso un sacudimiento provocador, por el nivel de reflexividad y complejidad que comenzaban a impulsar para comprender mejor las relaciones entre hombres y mujeres, siempre con la intención de configurar un acercamiento que trasladara lo esencialista diferenciado a lo discursivo significante.

1. Universidad Cristóbal Colón. Correo electrónico: gaguirre@aix.ver.ucc.mx.

2. Esto no quiere decir que no hayan intervenido otras disciplinas, pues de la historia a la psicología social podemos decir, mucho se ha contribuido para el desarrollo de estos estudios emergentes y hoy tan bien posicionados en el ámbito académico. 
Un paso adelante en esto fue buscar comprender cómo, desde los distintos posicionamientos de género, se tejen y ponen en práctica las lecturas que sobre el mundo social pueden tener quienes conforman una cultura particular; para lo cual nuestros elementos de representación y objetivación están permeados por concepciones construidas desde la condición genérica, la diferenciación sexual, entre otros factores culturales.

La indagación al respecto entró en los plexos culturales para comprender las estrategias vivenciadas de las densas y complejas dinámicas de socialización que cotidianamente articulan los sujetos sociales, quienes determinan y son determinados por una sociedad, y en donde podemos decir que se detectaron una variedad de estrategias de significación que devienen en la imposición de asimetrías y matrices culturales discriminatorias; características particulares de las relaciones humanas en la mayoría de las sociedades.

Es precisamente desde la configuración discursiva del mundo de vida, que el trabajo que pretendemos realizar busca indagar en la teoría y algunos referentes empíricos para entender las formas en que se determinan las prácticas, se construyen los imaginarios sociales alrededor de lo amoroso, donde categorías tales como género, cuerpo y amor pudieran arrojar luz al respecto.

En este caso, es importante señalar que la tarea final de este texto es realizar una aproximación teórica ubicada en un proceso de construcción del proyecto de investigación doctoral titulado Juventud, ciudad e imaginarios amorosos en una escenario multicultural, donde se pretende realizar un análisis de las prácticas y la configuración de los imaginarios amorosos en el puerto de Veracruz; para lo cual consideramos fundamental realizar una revisión teórico-conceptual que nos permita tener una anclaje discursivo, para desde allí establecer un primer nivel de lectura de algo tan complejo y polifónico como pueden ser las representaciones en torno al amor en las sociedades contemporáneas a la luz de los discursos de la multiculturalidad. Entendemos este trabajo como una suerte de trazos primarios para de allí desarrollar una competencia en el manejo de un discurso que reconocemos complejo: el género como perspectiva de trabajo.

En la búsqueda de facilitar el abordaje, el trabajo se revela en cuatro momentos: el primero es una aproximación a las formas en que se fue consolidando el discurso feminista en torno al género, el segundo paso es ver cómo estos estudios devinieron en la revisión de la sexualidad y la concepción del cuerpo como constructo socio-cognitivo, para entender muchas de las prácticas sociales que caracterizan a la especie humana; posteriormente realizaremos un recorrido por algunas concepciones sobre el amor, lo mismo desde el terreno de la literatura que del discurso académico, para culminar el texto con una conjunción posible que ponga en perspectiva no sólo cómo pueden vivir las prácticas amorosas los jóvenes de hoy, sino cómo en un escenario multi- 
cultural la diversidad genera representaciones mediacionalmente determinadas; en las cuales las identidades y los grupos de referencia son una dimensión obligada para comprender muchos de los procesos de interacción que devienen materialidad objetiva, vista a trasluz de los procesos interculturales.

\section{Los orígenes de una nueva mirada}

Una las aportaciones significativas que se hizo en la década de los setenta en el ámbito académico y científico fue la aparición de una corriente antropológica que vino a replantear el canon discursivo que caracterizaba la producción científica de aquellos años: la antropología de la mujer, entre cuyas tesis el llamado androcentrismo fue el objeto discursivo que se buscó desmontar, al reconocerlo como una dimensión presente en los marcos epistémicos desde los cuales se construía el conocimiento sobre el mundo social.

Para ello, la referencia a la visión personal del antropólogo, la distorsión como un asunto inherente al objeto de estudio y la parcialidad ideológica de Occidente fueron los ejes sobre los que descansó buena parte del discurso de esta forma crítica de ver las cosas.

Ante esto, la necesidad de un ejercicio analítico, reflexivo y propositivo que pusiera sobre la mesa de debate el asunto de una nueva mirada: sensibilidad, racionalidad y militancia caracterizarían el trabajo de las nuevas agentes de conocimiento: las mujeres antropólogas, quienes comienzan a desmantelar las estructuras discursivas androcéntricas.

El eje central del trabajo -proponían- debería ser el estudio de las mujeres por las mujeres; junto a ello, la exigencia de proponer un nuevo modelo teórico y analítico donde la perspectiva de género impulsará una novedosa manera de abordar los objetos de estudio, pues las formas discursivas -evidentemente masculinizadas - obligaban a un modelamiento para redefinir la teoría antropológica (De Moore, 1991). Una tarea que de ninguna manera resultaba fácil, pues, tal como sostiene Edwin Ardener:

Las estructuras sociales eminentemente masculinas inhiben la libre expresión de modelos alternativos y los grupos dominados deben estructurar su concepción del mundo a través del modelo del grupo dominante (citado por De Moore, 1991:15).

Sobra decir, entonces, que lo femenino (históricamente invisible en la teoría social) exigía la emergencia de modelos teórico-conceptuales distintos, por ello el llamado que De Moore hace para hacer frente a las "incoherencias conceptuales y analíticas" (De Moore, 1991:17) de la teoría disciplinaria, que hasta entonces era la dominante. 
Es en esta dimensión que la nueva antropología deviene en feminista y con ella un punto de vista que va del estudio de la mujer al estudio del género, de las relaciones entre hombres y mujeres en las sociedades humanas, atendiendo a dimensiones ideológicas, económicas y políticas, que de forma sistemática determinan las relaciones múltiples y complejas en la vida social.

De una perspectiva mas bien natural, en sus inicios, a una visión cultural de las diferencias, el estudio, el análisis y la interpretación de las formas de modelaje en el mundo relacional de hombres y mujeres (caracterizado por la subordinación y las relaciones diferenciales), han pasado por dimensiones epistémicas distintas, desde las cuales estas investigadoras han procurado conocer los imbricados mecanismos que los determinan:

Se intentó averiguar cómo y en qué situaciones las mujeres ocupan posiciones de poder y cómo lo ejercían. Esto llevó a la realización de un análisis crítico de la universalidad de la subordinación femenina, y se introdujeron matices y precisiones que modificaron y enriquecieron sustancialmente el conjunto de la teoría y la información antropológicas (Lamas, 2002: 26).

Es importante señalar que los alcances de los trabajos realizados pusieron sobre la mesa la forma como los mecanismos de estructuración impiden o frenan los intentos de la mujer para modificar su estatus social; aun cuando sería a partir de las características particulares de cada cultura que se manifiesta esta asimetría y diferenciación, lo cierto es que la constante sería la subordinación política de las mujeres, como grupo social, frente a los hombres (Lamas, 2002: 27).

Otro aspecto relevante fue la vertiente que siguieron los estudios, pues si mucho del trabajo se centraba en lo biológico, otras vertieron lo ideológico en las investigaciones, lo que provocó en muchos casos una ausencia de rigor metodológico en las investigaciones realizadas, las cuales solían caer en un reduccionismo culturalista.

Lo importante de todo esto es la puesta en escena de un debate que removía las formas relacionales de los procesos sociales: el campo de los discursos y los posicionamientos ante ello, llevó a fracturar el monolito académico gracias a una avanzada antropológica feminista que puso los puntos sobre las íes, para desde allí no sólo interpelar sino remover las estructuras que identificaban al mundo social hasta antes de este movimiento. En las prácticas sociales y culturales, se alentó un cambio que incidió en la vida cotidiana y sus distintas dimensiones: en lo sexual, en lo laboral, en la política, en el hogar, todo visto a la luz de la categoría de género, concepto que comenzó a ser del dominio público, donde se impulsaba una lectura distinta de las prácticas y los procesos sociales en conjunto, abriendo paso a las investigaciones a la postre llamadas estudios de género. 


\section{La invención de una categoría de análisis}

A lo largo de la historia reciente de los estudios sociales, la llegada del concepto género promovió una serie de cambios cismáticos al interior de la academia y la ciencia, al constituirse en una categoría analítica que, apoyada en la imaginación, el atrevimiento y la reflexión, logró edificar un marco teórico que replanteó los mecanismos de acercamiento a las complejas relaciones socioculturales, para devenir en concepto de vida (en muchos casos). El género, desde esta perspectiva, revela una mirada sensible y crítica de las antropólogas feministas, ensanchando las posibilidades de comprensión en torno a las intrincadas maneras en que lo masculino ha monopolizado no sólo las estructuras, sino también los procesos y con ello toda posibilidad de igualdad entre hombres y mujeres.

En la medida en que reconocemos que el concepto de género es un término complejo de aprehender por la dimensión teórica, cognitiva y de acción que conlleva, juzgamos pertinente aproximarnos a su desarrollo conceptual realizando una revisión autoral de nivel básico, para con ello establecer el eje semántico desde el cual podemos conducirnos para incorporarlo a un proyecto como el que pretendemos realizar.

Así, si nos remitiéramos a un nivel de esencialismo biológico, tendríamos que, en muchos diccionarios, la noción de género remite a la especie; particularmente, haciendo énfasis en aquellas cosas que les son comunes para favorecer sus particulares características. Sin embargo, trasladado a la especie humana, esto es el resultado de un reduccionismo diferencial que ha hegemonizado un discurso que deviene en una barrera léxica y práctica entre hombres y mujeres.

En consideración a la cualidad racional, social y emocional que como entes pensantes tenemos, es pertinente realizar una serie de matizaciones que nos conduzcan por los referentes culturales, para asumir desde allí una lectura más acorde con nuestras maneras de construir los imaginarios, ese lugar desde el cual es posible reconocer cómo se constituye ese conjunto de creencias, rasgos personales, actitudes, sentimientos, valores, conductas y actividades sobre las que se determinan las diferencias entre hombres y mujeres, todo ello a través de un sistemático proceso de construcción social asentado sobre varias características (Gregorio Gil: 2002).

La autora de referencia nos habla, a continuación, del proceso histórico, por un lado, y del proceso de jerarquización, por el otro. En el primero distingue el desarrollo promovido desde el Estado, el mercado de trabajo, los centros educativos, los textos mass-mediáticos, la ley, la familia, lo mismo que la vida cotidiana, gracias al mecanismo interpersonal que hace operar sus lógicas. Para el segundo caso, al hablar del ordenamiento jerárquico hace 
referencia a la primera característica para señalar que a todo aquello que se presente como masculino, en los procesos a que los casos remitan, se le suele atribuir mayor valor (Gregorio Gil, 2002).

Desde esta concepción, tenemos que todo constructo discursivo masculinizado por una referencia histórica venida a costumbre convencional y por conveniencia, suele ocupar en el orden jerárquico una posición de dominancia frente a su "contraparte" femenina. Es desde esta acción discrecional, que las diferencias entre hombres y mujeres se van entretejiendo hasta llegar a consolidar una forma de vida fraguada en lo discriminatorio, pues como nos dice Scott, (1986), así pensado y asumido el género, tendríamos que reconocerlo como un:

[...] elemento constitutivo de las relaciones sociales basadas en las diferencias que distinguen los sexos y forma primaria de relaciones de poder [mismo que] se expresa a lo largo del tejido de relaciones e instituciones (mercado, Estado), en símbolos, normas, prácticas políticas y sociales y en las identidades subjetivas (citado por Gregorio Gil, 2002).

Como podemos darnos cuenta, las maneras en que se ha construido la noción de género, en tanto catalizador de las diferencias entre los sexos, se han dado a lo largo del proceso de culturización de todo ser humano, entrando por todos los intersticios que deja la regulación de la vida social. Niños, adolescentes, hombres y mujeres, jóvenes, adultos y viejos, a lo largo de su historia y desde todas las vertientes de la vida social, van nutriendo una perspectiva de género institucionalizada, que facilita la consolidación de la diferencia entre los géneros sexuales cuando tramposamente se fundamenta en una distinción genética que - dicen- es de naturaleza humana. Lo que viene a continuación es el establecimiento de una serie de cuñas socioculturales que van allanando los caminos para introyectar discursos y prácticas sociales que terminan por conformar el habitus al que Bourdieu (1998) hace referencia, y, desde allí, el tejido práctico, cognitivo y discursivo sobre el cual se hace operable el mundo y la vida social.

Es importante señalar que tampoco se trata de dejar de reconocer las diferencias sexuales entre hombres y mujeres, pues es claro que ellos y ellas cumplen con funciones diferentes en la reproducción humana (y esto no está a discusión) (Subirats: 1998), pero también es cierto que, mientras las identidades construidas alrededor de lo sexual no sólo permeen sino también determinen las formas discriminatorias de la convivencia social, política y cultural, estaremos suponiendo que las experiencias vitales diferentes que podemos tener desde uno u otro sexo son determinantes. No obstante, tal como lo señala atinadamente Marina Subirats: 
Hoy no está dada qué parte de la identidad genérica proviene de la diferente experiencia sexual, de la diferencia de papeles reproductivos; y cuál es la parte que procede de la socialización en un género o en el otro, de la diferencia de experiencias generada no por la sexualidad y la reproducción sino por las prescripciones sociales (1998: 25$)$.

Asumimos como nuestra su postura, cuando sostiene que continuar pensando que las diferencias entre el hombre y la mujer por encima de la estricta diferencia de sexos es seguir recreando un mundo donde los sistemas de límites a la libertad y a la creatividad individuales son determinantes; lo que seguirá promoviendo la perpetuación de mecanismos que mutilan a los individuos, al obligarlos:

[...] a renunciar a partes de la experiencia humana para conformarse a unos patrones previamente establecidos, que muy frecuentemente no coinciden ni con sus aptitudes ni con sus deseos (Subirats, 1998: 26).

En todo caso, lo conducente - pareciera - es apostar por una tendencia a la desaparición del género tal y como se ha concebido siempre. Lo que ello supondría sería el establecimiento de una serie de acciones que condujeran a vivencias distintas entre hombres y mujeres; experiencias a todas luces complejas que tenderían a promover un cambio en las estructuras relacionales a cualquier nivel del desarrollo humano, pensado desde un largo proceso de entendimiento y comprensión de todas las implicaciones posibles. Algo, sin duda, nada fácil.

Con todo esto, si bien es cierto nuestras identidades individuales y colectivas han sido marcadas por el género (deviniendo en un elemento definidor de nuestra personalidad al ser distinguidos como hombres y mujeres desde el nacimiento), lo más difícil de modificar serían nuestros esquemas cognitivos, nuestros comportamientos junto a las maneras en que solemos nombrar al mundo; es decir, los mecanismos en que hacemos visible nuestra identidad construida. ${ }^{3}$

Es precisamente desde esto, que los textos culturales y las múltiples maneras de constitución del sistema social que permean las articulaciones y los nodos identificadores de la especie humana son parte del instrumental sociocognitivo con que nos asumimos hombres y mujeres: los gustos, las maneras de vestir, de hablar, de relacionarnos con los otros, de ser propensos o no a las manifestaciones emocionales, son soportes informacionales y referenciales que sientan los rangos de distinción de lo masculino y lo femenino.

3. Es importante señalar que la idea de lo femenino y masculino-será la coronación de una existencia social diferenciada y donde las creencias, valores y costumbres, desde los plexos de la conciencia, son marcas indelebles en la vida de todo individuo. 
Ante ello, la necesidad de considerar una especial atención al género como una categoría de análisis que nos acerque al cúmulo diferencial en que hombres y mujeres jóvenes asumen y construyen sus prácticas amorosas; cómo desde lo femenino y masculino se ha generado la configuración de un imaginario social que se recrea en los múltiples discursos y prácticas sobre los que se sostiene el mundo contemporáneo. De tal forma, las identidades mediacionales colectivas e individuales supondrían mecanismos diversos y diferenciales para impulsar representaciones sobre lo amoroso entre los públicos juveniles, lo que a todas luces pudiera resultar una experiencia sexual distinta, "cobijada" por las nociones de género. Es precisamente en esta dimensión que quisiéramos indagar para enriquecer los conocimientos que podamos obtener con un trabajo como el pretendido en torno a las prácticas y los imaginarios amorosos.

\section{Representaciones sobre la sexualidad y prácticas amorosas}

Dicho lo anterior, vale la pena explorar teóricamente lo que la sexualidad es culturalmente; en el entendido de reconocer en ella una variable que puede conducir las prácticas amorosas entre los jóvenes. Líneas arriba ya hemos señalado cómo se construye la diferencia sexual entre los géneros, cómo a partir de una diferencia genética indiscutible se promueve una diferencia cultural que tiende a discriminar a la mujer, negándole incluso su potencialidad de ciudadana y ser humano en toda la extensión de la palabra, pues en todo esto se entrecruzan rasgos políticos, económicos, sociales y culturales reproducidos históricamente.

Es precisamente en el terreno de lo social donde tendríamos que reconocer que la sexualidad es un atributo de los sujetos, de la sociedad y de las culturas; donde las relaciones, estructuras, instituciones y las esferas de la vida, deben ser vestidas a la luz de su constitución histórica, dialéctica.

Ya anteriormente se había dicho que el género tiene que ver con un complejo sistema de determinaciones, donde lo económico, social, jurídico, político, psicológico, cultural en lo extensivo, son las referencias de dominancia para pensar la diversidad y las "diferencias". Pero ha de ser en el sexo donde se tenga que reconocer el hecho biológico que plantea la dicotomía del ser macho o ser hembra, para "sólo" poder ser así.

Sin embargo, en la historia del hombre existen determinantes culturales, para lo cual los consensos alrededor de lo sexual se determinan desde los discursos hegemónicos; donde cada sociedad, cada grupo social tiene que asumir una serie de estereotipos en torno a lo masculino y lo femenino. Aun 
con esto, es oportuno señalar que, si bien hay un esencialismo biológico en esta concepción, también lo es que no siempre ha sido así, ni ha estado presente en todas las culturas, según se reporta en algunos trabajos de carácter antropológico. ${ }^{4}$

Es oportuno, entonces, señalar que, a decir de Foucault, lo relacionado con la sexualidad se tendría que poner en perspectiva para reconocer en ella un atributo constituido sobre tres ejes:

[...] la formación de los saberes que a ella se refieren, los sistemas de poder que regulan su práctica y las formas según las cuales los individuos pueden y deben reconocer como sujetos de esa sexualidad [sujetos sexuales, sujetos deseantes] (citado por Lagarde, 1997: 181).

Desde una conciencia individual, desde el proceso sociocognitivo de la propia hominización, hay un primer nivel de aproximación a lo que la sexualidad representa para las culturas humanas; lo que viene a continuación es reconocer que todo ello se ha decantado en un denso y complejo entramado de relaciones discrecionales, donde el orden y las interacciones en la vida social se determinan por los mismos procesos de objetivación. Es a partir de esto cuando las personas, sus representaciones e imaginarios individuales y colectivos, pasan a lo vivencial práctico en torno a lo sexual.

En este tenor, basta recordar que, precisamente:

[las] representaciones sociales son construcciones simbólicas que otorgan atribuciones a la conducta objetiva y subjetiva de las personas. El ámbito social es, más que un territorio físico, un espacio simbólico definido por la imaginación y determinante en la construcción de la autoimagen de cada persona: nuestra conciencia está habitada por el discurso social (Lamas, 2002: 101).

Situados aquí, para el caso de las prácticas amorosas entre los jóvenes citadinos hay una serie de imágenes que suponen un constructo representacional matizado por una postura ideológica, moral, religiosa que conduce a vivir esta experiencia de manera distinta, según sea el caso, al ser mujer, hombre, homosexual; ser bisexual, transexual; por pertenecer a un sector social, vivir en uno u otro lugar, ser joven o adulto. En muchas de tales prácticas se pueden reconocer los mismos referentes amorosos y las cosas que pueden producirse alrededor de su práctica, pero precisamente en las formas diferenciadas

4. Entre los trabajos de investigación sobresalientes al respecto, podríamos mencionar los recopilados por Martín y Voorhies en su La mujer un enfoque antropológico (1975), donde se exponen una serie de casos etnográficos que relatan la vida de los navajos, los mohave y los azande, de Norteamérica y África, respectivamente. En ellos podemos reconocer una valoración de la sexualidad más allá de las formas conocidas y legitimadas en occidente. 
estriba el proceso de la diversidad con que se construye el amor, se determinan sus prácticas y se vive la sexualidad humana.

Ya lo dice atinadamente Marcela Lagarde:

Sobre los cimientos de la sexualidad, se organizan otros aspectos de la autoidentidad -como los que se desprenden del resto de las adscripciones sociales y culturales: la clase social, el grupo lingüístico, nacional, religioso; etcétera, y se superponen y combinan con éstos y con la edad. A largo del ciclo vital, la sexualidad continúa siendo el núcleo definitorio del lugar que cada quien ocupa en el mundo, y de sus posibilidades de experiencia (1997: 186).

Para el caso del trabajo de investigación que queremos realizar, estos elementos constitutivos de la vida social son un factor que queremos considerar, pues sostenemos que en las sociedades contemporáneas, caracterizadas por lo multi e intercultural, lo diverso y distinto, hay una serie de concepciones sobre la sexualidad que suponen dispositivos relacionales que tamizan las interacciones y las prácticas culturales. De tal suerte, una mujer joven que vive la experiencia sexual en la ciudad, en poco se parece a aquellas prácticas propias de mujeres que habitan en otro tipo de espacios o lugares; pues en ello, los referentes, las biografías personales, llevan a experiencias distintas entre una y otras; algo que se repite, naturalmente, en el caso de los hombres. La forma de vivir el amor ideal y el amor carnal en las sociedades de hoy muestran tendencia diferenciadas en comparación con lo que hace algunos años se veía y podía decir al respecto. En este sentido:

[...] se puede afirmar que el comportamiento sexual ha sufrido cambios considerables en el transcurso de las dos últimas generaciones, sobre todo en lo que a las chicas se refiere. Antes, por ejemplo, únicamente se permitía a los jóvenes varones $-y$ sólo de forma no oficial y con un guiño- tener experiencias sexuales. Hoy, más de la mitad de las chicas (61\%) asume que es importante para las mujeres tener experiencias sexuales (Beck y Beck-Gernsheim, 2001: 35-36). ${ }^{5}$

En esto, la historia reciente de la civilización occidental, particularmente, supone un momento coyuntural cuando vivió la experiencia del replanteamiento que significó la revolución sexual, que - a decir de Anthony Giddens (2000) - no sólo se debe ver como un avance en la permisibilidad sexual, sino como una revolución de la autonomía femenina que impactó de manera sustancial al ámbito de lo masculino; junto a esto, un segundo factor: el

5. Si bien es cierto que estos datos corresponden a las mujeres alemanas, se dice que en el proceso de globalización hay una internacionalización juvenil, donde proyectos de vida alrededor del sentir y actuar del joven se reproducen de la misma manera en todas las culturas. 
florecimiento de una homosexualidad asumida, tanto en hombres como en mujeres; lo que sin duda sentó las bases para una nueva sexualidad, que sobrepasa en mucho la ortodoxia dominante en torno a este tema (2000: 36).

Es justo aquí cuando podemos poner en perspectiva lo amoroso, en tanto constructo culturalmente determinado. No cualquier tipo, sino más bien el llamado amor apasionado, aquel situado en los interiores de la vida cotidiana y que supone una dimensión emocional pero también carnal. Este sentimiento arrebatador que ha sido la clave de la literatura romántica, se traslada a las experiencias personales de los sujetos sociales, quienes asumen esta implicación emocional en el entendido de una relación directa con el otro reconocido.

En la vida cotidiana, las concepciones del amor y la sexualidad avanzan a contrapelo en una sociedad que guarda los vestigios idílicos que identificaron a las sociedades románticas de los siglos XVII y XIX, donde el amor romántico:

[...] desde sus orígenes [...] suscita la cuestión de la intimidad. Es incompatible con la lujuria, y con la sexualidad terrenal, no tanto porque idealizaba a la persona amada - aunque esto formase parte de la historia - sino porque supone una identidad psíquica, un encuentro de espíritus que es el carácter reparador (Giddens, 2000: 50).

Hoy, en una sociedad caracterizada por los relativismos, el hedonismo light, lo laxo en muchas de las prácticas sociales, la permisibilidad con que son capaces de vivir las prácticas amorosas los jóvenes exigen del investigador social un nivel de análisis y reflexividad que permita poner sobre la mesa un ejercicio crítico ante la diversidad de factores que determinan los oficios amorosos entre la juventud: en su dimensión moral, religiosa, sexual, sentimental, representacional, objetiva. Tarea sin duda compleja, por la cantidad de factores y mecánicas estructurantes del hacer social que deben ser tomados en cuenta.

A punto de terminar la búsqueda iniciada, lo anterior tiene que llevar a indagar en tres conceptos que, para nosotros, resultan complementariamente potentes en este análisis, cuyo dispositivo pudiera ser la perspectiva de género: el cuerpo, el amor y la cultura

\section{El cuerpo, la cultura y el amor}

El cuerpo experimenta, en el sentido fenomenológico, distintas sensaciones, placeres, dolores, y la sociedad le impone acuerdos y prácticas psicolegales y coercitivas. Todo lo social es vivenciado por el cuerpo (Lamas, 2002: 147) 
¿A dónde nos lleva este juicio de Martha Lamas? Seguramente a una lectura multidimensional de lo que culturalmente puede llegar a representar ese continente físico, biológico, pero igual cognitivo, emocional, que es transcendido cuando se ve interpelado por "otro igual" en los procesos de interacción. Es él quien puede aportarnos algunos hallazgos que enriquezcan la mirada tradicional que se tiene sobre el cuerpo, esa suerte de muro de continencia desde donde suele ejercerse una mediación significativa con el mundo relacional y objetivo.

La mirada que Margarita Baz (1999) nos propone al respecto es desde una postura de interpelación, al asegurar que:

[...] el cuerpo nos interroga de múltiples maneras; la sexualidad y el dolor, las fuerzas complejas que sostienen la vida, la subjetividad y las identidades, el tiempo y la muerte son algunos de los grandes temas que gravitan sobre una condición de experiencia que llamamos cuerpo (1999: 25).

Como podemos ver, el cuerpo es potencia manifiesta por la diversidad de signos que es capaz de producir ante la percepción de los otros; es él, el cuerpo, la objetivación física de nuestra presencia en este mundo, donde la avidez e inestabilidad, la fragilidad y finitud, la estética de la existencia y la muerte suponen un diálogo de principio y fin entre el sujeto y su mundo social. Ante esto, el cuerpo es el protagonista, por ser la entidad desde donde se configura la experiencia de ser en este mundo material, es placer y goce, movimiento y expresión; por ello, también, es ejercicio asertivo de la subjetividad relacional, de tal suerte que, propone Baz:

[...] el cuerpo tendría que ser concebido como historia, como campo de fuerzas donde palpitan las huellas de la vida pulsional y afectiva y se arraigan los códigos de la sociedad: lo más íntimo e inmediato y a la vez lo transindividual, el vínculo social sin el cual el cuerpo como historia no existiría (1999: 26).

Entendemos que asumir esta condición y concepción del cuerpo (desde lo representacional a lo objetivo, desde lo material a lo reflexivo), en un proyecto como el que queremos realizar, es innegable la necesidad de potenciar nuestra capacidad de percepción, para resemantizarlo en los usos discursivos, en el entendido que es allí donde - a decir de la teoría y las investigaciones antropológicas contemporáneas- se constituyen muchos de los referentes culturales desde los cuales se asumen las identidades genéricas y sexuales. Es decir, representaciones colectivas que llevan a la configuración de imaginarios compartidos, así como de mecánicas de objetivación social.

Considerar que, precisamente, el cuerpo es una suerte de bisagra que articula lo social con lo psíquico, es inobjetable, ya que allí encontramos los 
rasgos primarios en torno a la sexualidad y la identidad, la pulsión que nos mueve y la cultura que nos determina, sea en la carne o el inconsciente (Lamas, 2002: 159).

Cómo no tomar esta referencia para buscar comprender ciertas asimetrías culturales que pueden estar presentes en las mecánicas que construyen el amor desde lo femenino y lo masculino, desde la identidad del macho y la hembra, desde las variables culturales que determinan a hombres y mujeres. Es importante que nos demos cuenta de que los estereotipos alrededor del género y la diferencia sexual pueden arrojarnos un tipo de conocimiento diferente para entender esas cualidades de la vida amorosa de los jóvenes citadinos en el puerto jarocho.

En este momento, y después de apostar por una serie de referente teóricos para acompañarnos, creemos que se han delineado algunos trazos para dar claridad a algo que se sabe sumamente complejo: la cultura y el cuerpo, donde pareciera que la vida amorosa de las personas encuentra su génesis, al igual que su punto de llegada. Subrayar la importancia del cuerpo, la cultural y el amor como categorías para reflexionar en esta última parte del recorrido, es abogar no sólo por las formas lingüísticas o semánticas, sino representacionales, para en ellas encontrar el significado y el sentido que se le puede dar al ideal amoroso y sus diversas manifestaciones entre aquellos que conforman nuestros sujetos de estudio.

Reconocemos lo importante que es tener una dimensión simbólica de este proceso de construcción conceptual para analizar los intrincados mecanismos con que operan las sociedades, donde el sexo biológico diferenciado es la primera de las lecturas culturales que se hace del cuerpo humano. Genes, hormonas, órganos reproductivos internos y externos, signan rasgos característicos que le son propios a uno y otro género. La identidad biológica a partir del sexo biológico sienta las bases de referencia para proceder al establecimiento de las distinciones primarias entre un hombre y una mujer, lo que deviene en negación o permisibilidad para explorar la propia entidad física sexuada.

En tal sentido, hombre y mujer se mueven en un entramado de significaciones en torno al sexo, que se va construyendo desde esta dicotomía genuinamente biológica pero resemantizada culturalmente. Es, precisamente, desde aquí que cada cultura, al oponer hombre-mujer, erige una serie de significaciones que articulan una trama de sentido que lo mismo tiene una dimensión simbólica que real.

Es desde aquí que el cuerpo humano y su estructura sufren una somatización cultural arbitraria (Lamas, 2002: 108), que incide en procesos inconscientes pero igual en determinantes sociales, pues en los esquemas sociocognitivos hay una re-producción que se construye desde el reconocimiento del mundo material, que más tarde se objetiva en la representación del continente corpo- 
ral, que deviene en una diferenciación sexual estructurante psíquica y simbólicamente.

Los puntos finos en todo esto serían la multiplicidad de percepciones desde las cuales construimos el mundo social. $Y$ en esto, sin duda, la idea del amor y sus prácticas arrojan una diversidad fenomenológica propia del interactuar de los sujetos sociales. Recordemos que si bien el amor es una práctica intersubjetiva, donde intervienen dos o más sujetos, también lo es que se construye socialmente desde la determinación de atributos individuales, donde cada uno ha incorporado a sus comportamientos y hábitos de vida ciertas concepciones y maneras de vivir lo amoroso, que terminan por incidir en la vida práctica sentimental.

Desde sus imaginarios sociales y culturales, hombres y mujeres determinan sus prácticas; es en ellos y desde ellos donde se manifiestan las formas particulares de reproducción de lo amoroso, pues tal como dijera Octavio Paz:

[...] el amor es individual o, más exactamente interpersonal: queremos únicamente a una persona y le pedimos a esa persona que nos quiera con el mismo efecto exclusivo. La reciprocidad requiere la reciprocidad, el acuerdo del otro, su voluntad (2001: 117).

Sin embargo, también es cierto que, cultural e históricamente, los hombres tienen menores exigencias para cumplir con esta reciprocidad, cosa que no ocurre entre las mujeres, cuyos atavismos sociales y culturales les impiden potenciar su vida sentimental y sexual; lo que supone, entonces, maneras distintas de vivir y asumir lo amoroso. $Y$ aun cuando entendamos que en una relación de pareja "cada uno está en relación con los otros, cada uno determina y es determinado por ellos" (2001: 117), socialmente los requerimientos que se le hacen al hombre en una relación de pareja son más laxos que los del caso femenino.

Por otro lado, es importante señalar que, desde la perspectiva de género, es posible encontrar un marco teórico que arroje claridad sobre la complejidad del amor y las relaciones de pareja en las sociedades contemporáneas, pues precisamente en las asimetrías culturales, en el denso entramado sobre el que se mueven las relaciones interculturales, en la diversidad y las diferencias posibles entre hombres y mujeres, en las matrices de lo femenino y masculino; en fin, en todo aquello que sienta la diversidad y la diferencia (sin duda presentes en las ciudades contemporáneas), sentimos que podemos hallar razones para explicar y comprender mejor todo lo que mueve a las representaciones y las prácticas que del amor existen entre los públicos juveniles.

Hay que señalar que es en las postrimerías de la adolescencia donde no sólo se consolidan una serie de imágenes al respecto, sino que se va erigiendo 
una concepción del amor que va de lo imaginal a lo concreto (pues con la juventud entran a la escena social otras posibilidades vivenciales, al trazar los rasgos emergentes de la vida sentimental generacional: desde el crecimiento del cuerpo y la maduración sexual producida por el desarrollo hormonal), la emancipación social juvenil y el ingreso a un grupo de referencia le dan al joven una mayor posibilidad de desarrollarse y vivir su libertad; lo que representa una serie de factores que, a decir de Francesco Alberoni (1997: 102), generan un cambio sustancial en la vida de las personas y, con ello, en lo social.

\section{Apuntes (in)conclusos}

Hablar de prácticas amorosas entre los jóvenes, por un lado, es entrar en los pliegues de lo cultural y social para entender, explicar y comprender desde el terreno de las prácticas cotidianas a uno de los sectores sociales distintivos de las sociedades de hoy; por el otro, tendríamos que reconocer la dimensión cognitiva para analizar los rasgos ideológicos desde los cuales se vive y practica el amor juvenil en las sociedades urbanas. ${ }^{6}$

Con esto queremos apuntar que la ciudad genera una matriz ideológica y cultural importante en la construcción de los imaginarios sociales, pues en las ciudades y desde su significación es que se elaboran las ideas del ser citadino $y$, con esto, el establecimiento de patrones culturales donde las prácticas amorosas son, sin duda, un referente potente. Para ello, ha sido necesario tener un registro del menú de posibilidades con que se conduce quien vive en una ciudad, donde la oferta cultural, el uso territorializado de los espacios, así como los hábitos de consumo, suponen un rasgo de distinción y reproducción en todo lo que los sujetos sociales hacen o dejan de hacer. Y en ello el amor, el género, la sexualidad, pueden llegar a ser categorías fundamentales para entender y comprender lo que son los jóvenes vistos a la luz de los tiempos que corren, donde discursos como el multiculturalismo y la interculturalidad pueden proponer marcos epistémicos y teóricos para trazar una línea de trabajo emergente, además de ofrecer la ocasión de ver de manera distinta los procesos sociales y culturales que identifican a los jóvenes de nuestras ciudades.

6. Es oportuno señalar que el proyecto puesto en marcha toma a la ciudad como el espacio no sólo geográfico sino también simbólico, que caracteriza al mundo en tiempos de la globalización, y en donde se genera un potencial intercultural, presente no sólo en las asimetrías culturales sino también en las maneras en que operan las relaciones sociales y se configuran las identidades individuales y colectivas. 


\section{Bibliografía}

Alberoni, Francesco (1997), El primer amor, España, Gedisa.

Beck, Ulrich y Elizabeth Beck-Gernsheim (2001), El normal caos del amor. Las nuevas formas de la relación amorosa, España, Paidós.

Baigorri, Artemio (1995), “Género y espacio. Segregación social vs. segregación espacial”, v Congreso Español de Sociología. Granada. Grupo 6. Sociología urbana. Sesión $2^{a}$. Usos del espacio y diferencias de género.

Baz, Margarita (1999), "El cuerpo en la encrucijada de una estética de la existencia”, en Carrizosa Hernández, Silvia (comp.), Cuerpo: significaciones e imaginarios, México, UAM.

Bourdieu, Pierre (1998), Cosas dichas, Buenos Aires, Argentina, Gedisa. Giddens, Anthony (2000), La transformación de la intimidad. Sexualidad, amor y erotismo en las sociedades modernas, Madrid, Cátedra.

Gregorio Gil, Carmen (2002), Relaciones de género y migraciones internacionales (texto incluido en la antología para el curso doctoral Relaciones de género y migraciones internacionales, del Doctorado en Sociedades multiculturales y estudios interculturales), Jalapa, México.

Katchadourian, Herant A. (comp.) (2000), La sexualidad humana. Un estudio comparativo de su evolución, México, FCE.

Lagarde, Marcela (1997), Los cautiverios de las mujeres: madresposas, monjas, putas, presas y locas, México, UNAM.

Lamas, Marta (2002), Cuerpo: diferencia, sexualidad y género, México, Taurus.

Lipovetsky, Gilles (1994), El crepúsculo del deber. La ética de los nuevos tiempos democráticos, Barcelona, Anagrama.

Paz, Octavio (2001), La llama doble. Amor y erotismo, México, Seix Barral.

Rougemont, Deni de (1999), Los mitos del amor, Barcelona, Kairón.

Subirats, Marina (1998), Con diferencia. Las mujeres frente al reto de la autonomía, Barcelona, Icaria-Antrazyt. 